\title{
Diabetes induces the activation of pro-ageing miR-34a in the heart, but has differential effects on cardiomyocytes and cardiac progenitor cells
}

\author{
Ingrid Fomison-Nurse ${ }^{1}$ Eugene Eng Leng Saw ${ }^{1} \cdot$ Sophie Gandhi ${ }^{1}$ Pujika Emani Munasinghe ${ }^{1}$ Isabelle Van Hout ${ }^{1}$. \\ Michael J.A Williams $\mathbb{1}^{2} \cdot$ Ivor Galvin ${ }^{3} \cdot$ Richard Bunton $^{3} \cdot$ Philip Davis $^{3} \cdot$ Vicky Cameron $^{4} \cdot$ Rajesh Katare $\mathbb{D}^{1}$
}

Received: 10 July 2017 / Revised: 23 November 2017 / Accepted: 27 November 2017 / Published online: 4 January 2018

(c) The Author(s) 2018. This article is published with open access

\begin{abstract}
Increased apoptosis and premature cellular ageing of the diabetic heart underpin the development of diabetic heart disease. The molecular mechanisms underlying these pathologies are still unclear. Here we determined the role of pro-senescence microRNA (miR)-34a in accelerating the ageing of the diabetic heart. RT-PCR analysis showed a significant increase in the level of circulating miR-34a from early stages in asymptomatic type-2 diabetic individuals compared to non-diabetic controls. We also observed significant upregulation of miR-34a in the type-2 human diabetic heart suggesting circulating miR-34a may be cardiac in origin. Moreover, western blot analysis identified marked downregulation of the pro-survival protein sirtuin 1 (SIRT1), a direct target of miR-34a. Analysis of cultured human adult cardiomyocytes exposed to high glucose and cardiac progenitor cells (CPCs) isolated from the diabetic heart confirmed significant upregulation of miR-34a and downregulation of SIRT1, associated with a marked increase in pro-apoptotic caspase-3/7 activity. Although therapeutic inhibition of miR-34a activity restored SIRT1 expression in both cardiomyocytes and CPCs, p53 expression was further upregulated in cardiomyocytes but conversely downregulated in CPCs. In spite of increased p53, miR-34a inhibition significantly reduced high glucose induced apoptotic cell death in cardiomyocytes. However, this effect was not observed in CPCs, which in fact showed reduced proliferation following miR-34a inhibition. Taken together, our results demonstrate upregulation of miR-34a in the diabetic heart and in the circulation from an early stage of the disease. However, inhibition of miR-34a activity has differential effects depending on the cell type, thereby warranting the need to eliminate off-target effects when introducing miR-based therapy.
\end{abstract}

Edited by Y. Shi

Eugene Eng Leng Saw and Sophie Gandhi contributed equally to this work.

Electronic supplementary material The online version of this article (https://doi.org/10.1038/s41418-017-0047-6) contains supplementary material, which is available to authorized users.

Rajesh Katare

rajesh.katare@otago.ac.nz

1 Department of Physiology, HeartOtago, School of Biomedical Sciences, University of Otago, Dunedin, New Zealand

2 Department of Medicine, Dunedin School of Medicine, University of Otago, Dunedin, New Zealand

3 Department of Cardiothoracic Surgery, Dunedin School of Medicine, University of Otago, Dunedin, New Zealand

4 Christchurch Heart Institute, University of Otago, Christchurch, New Zealand

\section{Introduction}

Cardiovascular disease is the leading cause of death in diabetic individuals, with diabetics possessing a two to three times increased risk of developing heart disease compared to their non-diabetic peers [1]. Diabetes has a global effect on the heart leading to a progressive loss of cardiovascular cells thereby accelerating cardiac ageing. We, along with others, have shown that early molecular alterations in the diabetic heart lead to the loss of cardiomyocytes [2,3], endothelial cells [4, 5], and stem cells $[6,7]$, resulting in structural and functional deterioration. This phenomenon is commonly referred to as diabetic heart disease (DHD) which clinically encompasses the development of coronary artery disease, diabetic cardiomyopathy, heart failure, and coronary heart disease [8].

The causes behind the development of DHD are not completely elucidated, although recent studies suggest increased apoptosis and premature cellular ageing in the 
diabetic heart as major mechanisms that underpin the development of DHD [9, 10]. The exact molecular mechanisms underlying these pathologies are still not clear. MicroRNAs (miR) are gaining interest as key molecular mediators of several pathophysiological processes, and also show potential as sensitive biomarkers for various diseases including cardiovascular diseases $[11,12]$.

The miR-34 family consists of three families with miR$34 \mathrm{a}$ on human chromosome $1 \mathrm{p} 36$, and miR-34b and miR-34c co-transcribed on human chromosome 11q23 [13]. Among the three family members, miR-34a is abundantly expressed in cardiomyocytes [14, 15]. MiR-34a has been linked to the regulation of several proteins including Akt [16], PNUTS (also known as Ppp1r10) [14], and sirtuin 1 (SIRT1) [17], all of which have actions relevant to the diabetic heart. Akt is important in the translocation of GLUT4 to the membrane [18], while PNUTS is involved with glucose metabolism and DNA repair in the heart [14]. SIRT1 is an enzyme implicated in the deacetylation of proteins involved in cell stress, longevity, and glucose metabolism [19]. Importantly, knockdown of miR-34a in the heart of aged mice reduced hypertrophic growth and improved the cell survival, as compared to wild-type heart [14].

In this study, we aimed to investigate whether miR-34a is altered in the diabetic heart. We have demonstrated for the first time a marked upregulation in the level of circulating miR-34a from the early stages of diabetes in otherwise healthy individuals. We also show a marked increase in miR-34a expression in the human diabetic myocardium, and isolated cardiac progenitor cells (CPCs). Interestingly, in vitro knockdown of
miR-34a in cultured human ventricular cardiomyocytes and CPCs showed contrasting effects on cell survival, apoptosis, and proliferation. Altogether, our data suggest that miR-34a has differential effects depending on cell type in cell pathways associated with the progression of DHD.

\section{Results}

\section{Early upregulation of circulating miR-34a level in diabetic individuals}

Our first aim was to determine whether diabetes modulates miR-34a expression from the early stages of the disease. Quantitative RT-PCR analysis showed a significant increase in the expression level of miR-34a in the RNA extracted from the plasma of diabetic individuals who were otherwise healthy (Fig. 1a). Statistical analysis showed a significant increase from 5 years after the onset of diabetes, which was sustained and further increased with the duration of the disease (Fig. 1a). Interestingly, regression analysis showed a significant positive correlation between miR-34a expression and $\mathrm{HbA} 1 \mathrm{c}$ level suggesting a direct effect of glucose on miR-34a expression levels (Fig. 1b).

\section{Upregulation of miR-34a expression in human diabetic heart}

To determine whether the increased expression of circulating miR-34a is associated with increased expression of
Fig. 1 Early upregulation of miR34a in diabetic individuals. Quantitative scatter plots showing the differential expression of circulating miR-34a by quantitative RT-PCR analysis in the plasma collected from type- 2 diabetic individuals with no history of cardiovascular disease at different diabetes duration $(n=11-14$ at each time point). Age-matched nondiabetics (ND) served as control ( $n$ $=32$ ). Data are expressed as log-fold change in miR-34a expression and are mean \pm SEM. $* * P<0.01$ and *** $P<0.001$ vs. ND; ${ }^{\# \#} P<0.01$ vs. diabetic $<5$ years duration by oneway ANOVA. b Scatter plots of plasma $\mathrm{HbA} 1 \mathrm{c}$ and circulating miR34a in all the samples used for the study irrespective of the presence or absence of diabetes. There was a strong positive correlation between $\mathrm{HbA} 1 \mathrm{c}$ level and miR-34a expression, and this association was statistically significant
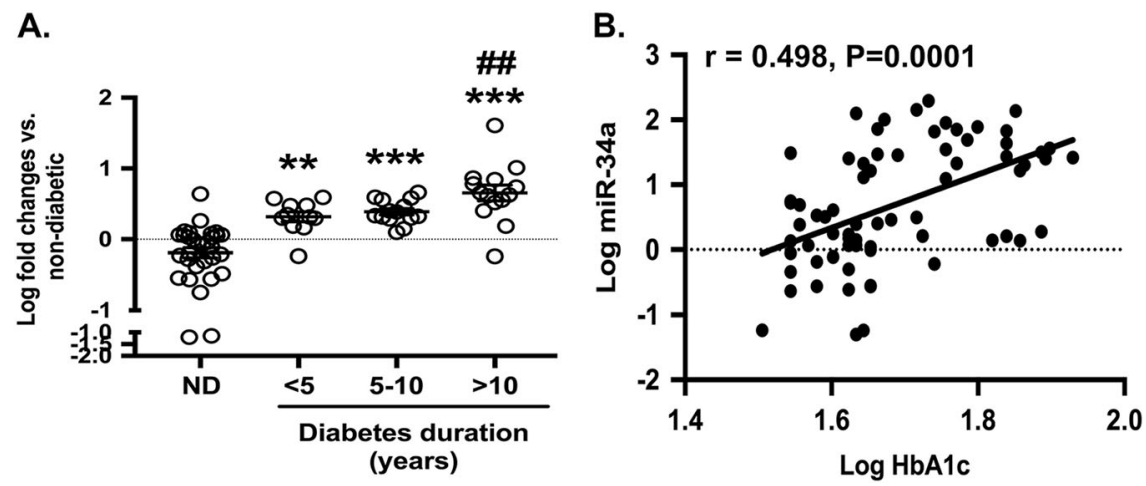
Table 1 Clinical characteristics of study participants with ischemic heart disease

\begin{tabular}{|c|c|c|c|c|c|c|c|c|c|}
\hline & $\begin{array}{l}\text { Study } \\
\text { participant } \\
\text { ID }\end{array}$ & Age & Sex & $\begin{array}{l}\text { Diabetes } \\
\text { duration } \\
\text { (years) }\end{array}$ & $\begin{array}{l}\text { Body } \\
\text { weight } \\
(\mathrm{kg})\end{array}$ & $\begin{array}{l}\text { Body } \\
\text { Mass } \\
\text { Index }\end{array}$ & $\mathrm{HbA1C}$ & LVEF (\%) & $\mathrm{E} / \mathrm{A}$ ratio \\
\hline \multirow{18}{*}{$\begin{array}{l}\text { Non- } \\
\text { diabetic }\end{array}$} & 79 & 56 & M & - & 82.5 & 29.6 & 44 & 55 & 0.95 \\
\hline & 85 & 71 & M & - & 70.5 & 24.4 & - & 30 & 2.6 \\
\hline & 86 & 88 & F & - & 66.5 & 26.9 & 45 & 47 & 0.58 \\
\hline & 78 & 64 & M & - & 76.9 & 25.4 & 43 & 31 & 4.3 \\
\hline & 83 & 53 & M & - & 88 & 30.5 & 37 & 35 & 0.66 \\
\hline & 88 & 60 & M & - & 110 & 33.2 & 39 & 50 & N/A \\
\hline & 89 & 66 & M & - & 94.7 & 28.4 & 32 & 68 & 1.39 \\
\hline & 98 & 54 & $\mathrm{~F}$ & - & 118.3 & 40.4 & 35 & 55 & 1.48 \\
\hline & 100 & 83 & M & - & 68.8 & 24.7 & 37 & 65 & 0.72 \\
\hline & 104 & 66 & M & - & 101 & 34.9 & 44 & 39 & 1.44 \\
\hline & 106 & 47 & M & - & 105 & 36.3 & - & 56 & 1.27 \\
\hline & 107 & 71 & M & - & 82 & 28.5 & 41 & 69 & 1 \\
\hline & 108 & 69 & M & - & 108.9 & 33.3 & 44 & 30 & N/A \\
\hline & 110 & 58 & M & - & 86.6 & 30.2 & 38 & 57 & 0.86 \\
\hline & 113 & 64 & M & - & 130.2 & 40.19 & 41 & 49 & 1.62 \\
\hline & 97 & 72 & $\mathrm{~F}$ & - & 80.4 & 29.9 & 35 & 59 & 3.15 \\
\hline & 127 & 65 & M & - & 84 & 25.925 & 37 & 62 & 0.63 \\
\hline & 139 & 55 & $\mathrm{~F}$ & - & 57.8 & 22.08 & 35 & 59 & 1.62 \\
\hline \multirow[t]{15}{*}{ Diabetic } & 84 & 73 & M & 8 & 72.6 & 25.3 & 58 & 73 & 1.02 \\
\hline & 122 & 77 & $\mathrm{~F}$ & 13 & 78.7 & 29.58 & 43 & 47 & 0.48 \\
\hline & 80 & 57 & $\mathrm{M}$ & 2 & 98.9 & 33.8 & 62 & 31 & 3.7 \\
\hline & 82 & 69 & $\mathrm{M}$ & 5 & 105.7 & 34.5 & 55 & 30 & 1.49 \\
\hline & 103 & 62 & $\mathrm{M}$ & 11 & 102.4 & 34.7 & 74 & 63 & 0.98 \\
\hline & 131 & 66 & M & 20 & 83 & 26.26 & 57 & 27 & 0.48 \\
\hline & 134 & 68 & M & 2 & 93.8 & 32.15 & 51 & 56 & 0.7 \\
\hline & 92 & 62 & M & 4 & 114.5 & 36.5 & 53 & 57 & N/A \\
\hline & 105 & 77 & M & 17 & 76.11 & 23.8 & 86 & 71 & N/A \\
\hline & 123 & 83 & M & 8 & 63 & 23.71 & 49 & 41 & 0.62 \\
\hline & 72 & 70 & $\mathrm{M}$ & 15 & 77.2 & 24.4 & 43 & 28 & 1.23 \\
\hline & 111 & 72 & $\mathrm{~F}$ & 4 & 69.8 & 25.8 & 44 & 65 & 0.6 \\
\hline & 121 & 60 & M & 5 & 153 & 49.96 & 42 & 62 & 1.48 \\
\hline & 128 & 62 & $\mathrm{~F}$ & 12 & 86 & 31.59 & 68 & 82 & 1.67 \\
\hline & 135 & 48 & M & 20 & 101.6 & 33.79 & 79 & 60 & 1.3 \\
\hline
\end{tabular}

HbA1c - Glycated haemoglobin; LVEF - left ventricular ejection fraction.
miR-34a in the heart, we next measured the expression of miR-34a in RAA tissue collected from type- 2 diabetic and non-diabetic patients undergoing coronary artery bypass graft surgery for ischaemic heart disease (IHD). Type of disease and other clinical parameters were comparable between both the groups, although patients with diabetes had a higher level of HbA1c (Table 1). As above, there was a significant correlation between miR-34a and HbA1c (Fig. 2c). RT-PCR analysis confirmed significant expression of miR-34a in the diabetic heart (Fig. 2a). This was also reflected in the plasma showing a significant increase in the level of miR-34a expression in diabetic patients
(Fig. 2b) confirming that high levels of circulating miR-34a observed in healthy diabetic individuals (Fig. 1a) may be partly due to a high level in the heart. Further, as in the healthy diabetic group, the level of miR-34a expression showed a significant positive correlation to the duration of diabetes (Fig. 2d).

\section{Dysregulated expression of miR-34a target proteins in human diabetic heart}

Next, to understand the functional effects of increased miR$34 \mathrm{a}$, we measured the expression of Akt, PNUTS, and 
Fig. 2 Upregulation of miR-34a in diabetic heart. $\mathbf{a}, \mathbf{b}$

Quantitative scatter plots

showing the differential

expression of miR-34a by

quantitative RT-PCR analysis in the right atrial appendage $\mathbf{a}$ and plasma b collected from type- 2 diabetic and age-matched nondiabetic individuals undergoing on-pump coronary artery bypass graft surgery. Data are expressed as log-fold change in miR-34a expression and are mean \pm SEM. $* P<0.05$ and $* * P<0.01$ vs. non-diabetic. c, $\mathbf{d}$ Scatter plots showing the correlation between plasma $\mathrm{HbA} 1 \mathrm{c}$ and myocardial miR-34a c or miR$34 \mathrm{a}$ and diabetes duration $\mathbf{d}$.

There was a positive correlation for both $\mathrm{HbA} 1 \mathrm{c}$ level and diabetes duration with myocardial miR-34a expression, and this association was statistically significant. $n=11$ in non-diabetic and 10 in diabetic
A.

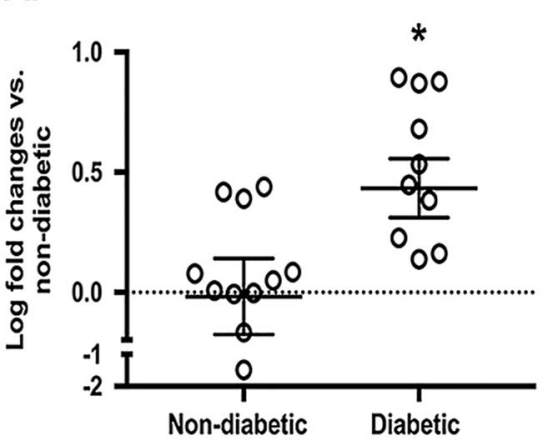

C.

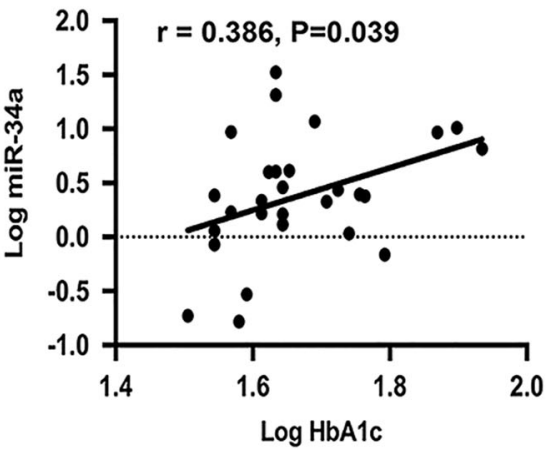

B.

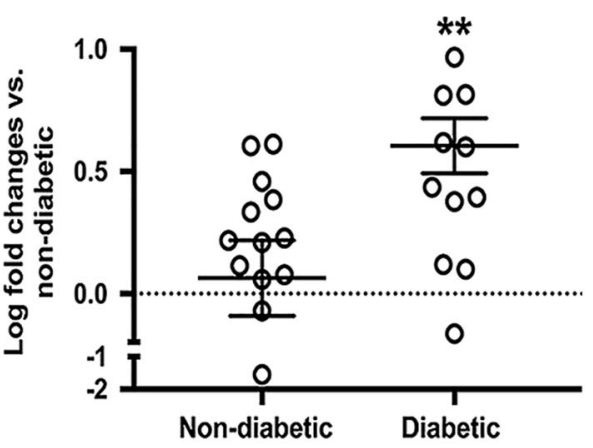

D.

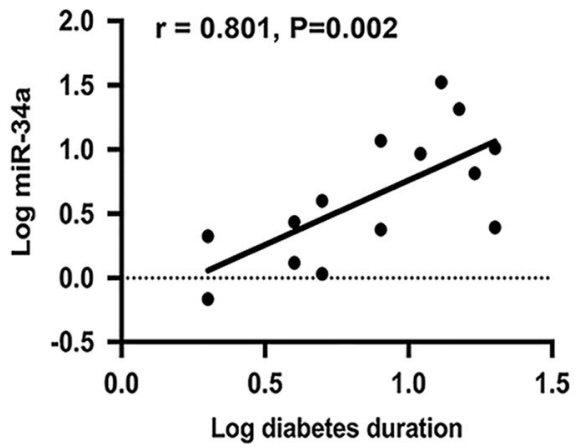

SIRT1, three known protein targets of miR-34a in human heart tissue. Interestingly, western blot analysis showed no significant difference in the expression of both Akt (Fig. 3a) and PNUTS (Fig. 3b). However, diabetes induced a significant downregulation of SIRT1 (Fig. 3c) in the heart. SIRT1 is a key protein associated with cellular longevity, suggesting that upregulation of miR-34a could be one of the major factors for increased apoptosis and senescence in the diabetic heart. As expected, regression analysis showed a negative correlation between SIRT1 and the expression of miR-34a in the myocardium which was statistically significant (Supplementary Fig. 1). As diabetes accelerates senescence, and the diabetic heart showed a downregulation of SIRT1, we next measured the expression of p53 in the diabetic heart. In contrast to our expectations the diabetic heart did not show any increase in the expression of $\mathrm{p} 53$ (Fig. 3d).

\section{Increased expression of miR-34a in diabetic human CPCs and high glucose cultured human cardiomyocytes}

RT-PCR analysis confirmed increased expression of miR-34a in high glucose cultured AC-16 cardiomyocytes (Fig. 4a). This was associated with a marked downregulation of SIRT-1 (Fig. 4b). In contrast to the expression pattern in the diabetic heart, high glucose exposed cardiomyocytes showed a marked increase in the expression of pro-apoptotic and pro-senescent p53 (Fig. 4c), leading to increased apoptotic cell death (Fig. 4d).

CPCs were characterized using CD90 and CD105 surface antigens. FACS analysis showed significant downregulation of CD90 expression in diabetic CPCs (Fig. 5a) with no difference in CD105 population. Although CD105 is considered as the major CPC, our earlier studies showed the crucial role for CD90 in CPC migration [20]. Reduced CD90 in diabetic CPCs therefore suggest impaired migration in diabetic CPCs. There was no difference in the differentiation potential of diabetic CPCs compared to the nondiabetic CPCs (Fig. 5b). Similar to the cardiomyocytes, RTPCR analysis showed a significant upregulation of miR-34a in diabetic CPCs (Fig. 5c), which was associated with marked downregulation of SIRT-1 (Fig. 5d) and significant upregulation of p53 expression in diabetic CPCs (Fig. 5e). Although the diabetic CPCs showed an increase in caspase$3 / 7$ activity (Fig. 5f), this was significantly less compared to the caspase-3/7 activity in high glucose cultured cardiomyocytes (Fig. 4d), even after controlling for seeding density and cell number.

\section{Therapeutic inhibition of miR-34a activity has differential effects on cardiomyocytes and CPCs}

Finally, to determine the beneficial role of therapeutic inhibition of miR-34a, AC-16 cardiomyocytes, and 
Fig. 3 Dysregulated expression of miR-34a target protein in human diabetic heart. Representative immunoblot images and quantitative bar graphs showing the expression of Akt a, PNUTS b, SIRT-1 $\mathbf{c}$ and $\mathrm{p} 53 \mathbf{d}$ in diabetic and nondiabetic groups. $\beta$-actin was used as internal control. $n=$ at least 7 each. Data are represented as ratio of corresponding protein and $\beta$-actin and are mean \pm SEM. $* P<0.05$ vs. non-diabetic
A.

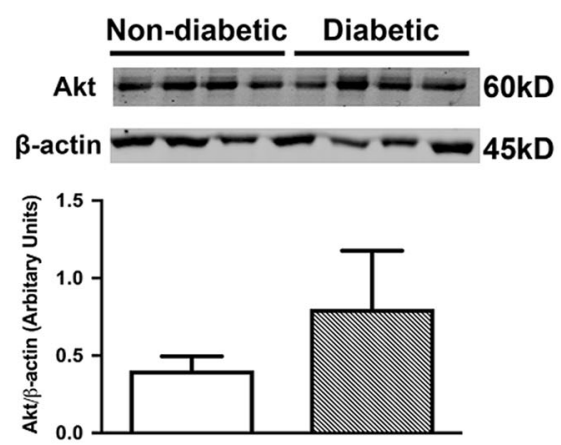

C.

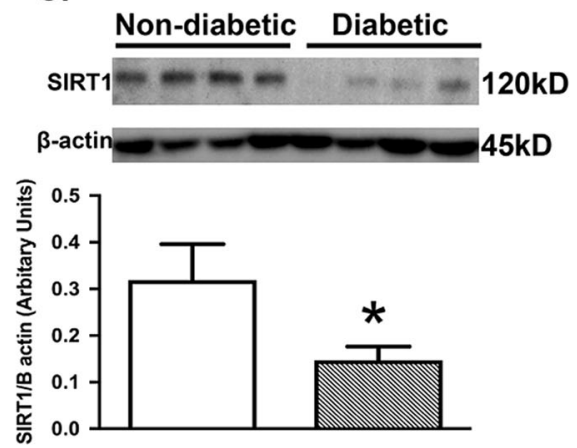

B.
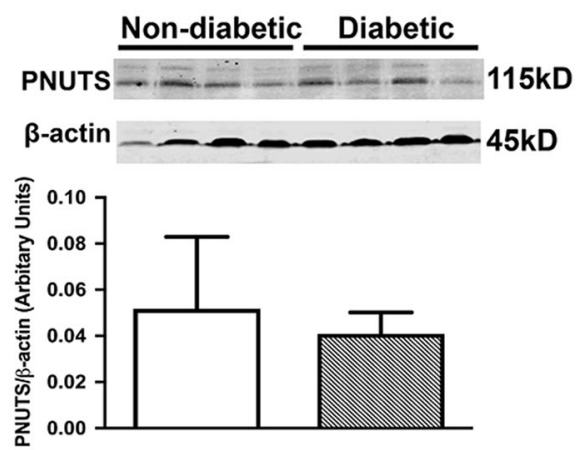

D.
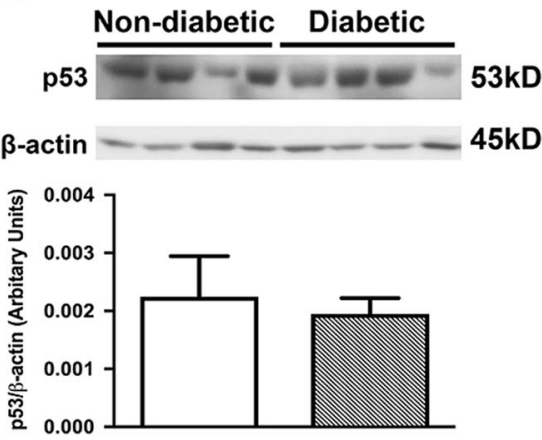

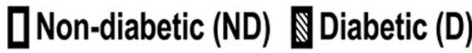

CPCs were treated with high glucose with or without inhibition of miR-34a activity. Inhibition of miR-34a activity restored the expression of SIRT1 in both cardiomyocytes and CPCs (Figs. 6a and 7a). However, inhibition of miR-34a had differential effects on p53 expression in high glucose cultured cardiomyocytes and diabetic CPCs. Following inhibition of miR-34a activity, there was a significant increase in the p53 expression in cardiomyocytes (Fig. 6b), while CPCs showed a significant downregulation in p53 (Fig. 7b). More interestingly, irrespective of this increased p53 expression, inhibition of miR$34 \mathrm{a}$ activity resulted in marked reduction of high glucose induced apoptotic cell death in cardiomyocytes (Fig. 6c), while CPC did not show any such improvement (Fig. 7c). Indeed there was a trend towards an increase (not statistically significant) in the level of apoptosis in CPCs treated with anti-miR-34a (Fig. 6c). Importantly, inhibition of miR-34a activity significantly reduced the proliferation of diabetic CPCs (Fig. 7d). These results demonstrate a differential role of miR-34a on cardiomyocytes and CPCs, which is likely to be due to the difference in the expression pattern of p53 following inhibition of miR-34a.

\section{Materials and methods}

\section{Ethics}

Collection of human right atrial appendage and blood samples has been approved by the Health and Disability Ethics Committee of New Zealand (Healthy Volunteers Ethics Reference: Upper South A Ethics Committee Approval No. 01/05/062). All patients provided written consent for collection and use of samples in this study. Collection and use of the human samples conformed to the Declaration of Helsinki.

\section{Plasma sample collection from healthy donors}

Peripheral blood samples were collected from type-2 diabetic individuals without any known history of cardiovascular disease who volunteered in the "Canterbury Healthy Volunteers for the Study of Heart Disease" through the Christchurch Heart Institute. Volunteers were divided into three groups according to the duration of diabetes $(<5$ years, 5-10 years, and $>10$ years). Age and gender matched non-diabetic volunteers served as controls (Table 2). 
Fig. 4 High glucose treatment upregulates miR-34a in cultured

human cardiomyocytesa

Quantitative scatter plots

showing the differential

expression of miR-34a by quantitative RT-PCR analysis in the AC-16 human ventricular cardiomyocytes cultured under normal glucose (NG) or high glucose (HG). Equal concentration of mannitol was added to the NG cultured cells as the osmotic control. Data are expressed as Log fold change in miR-34a expression and are mean \pm SEM. b, c

Representative immunoblot images and quantitative bar graphs showing the expression of SIRT-1 b and p53 $\mathbf{c}$ in HG and NG cultured

cardiomyocytes. $\beta$-actin was used as internal control. Data are represented as fold changes to NG cultured cells and are mean \pm SEM. d Quantitative bar graphs showing the caspase-3/7 activity in NG and $\mathrm{HG}$ cultured cells. Data are represented as relative luciferase units and are mean \pm SEM. $* P<0.05$ nd $* * * * P<0.001$ vs. normal glucose (NG) treated cells. All the experiments were performed in triplicates
A.

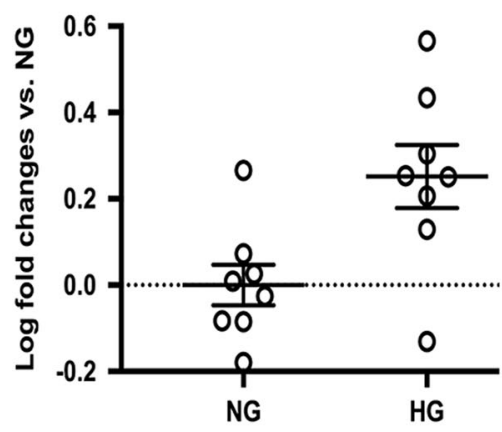

C.
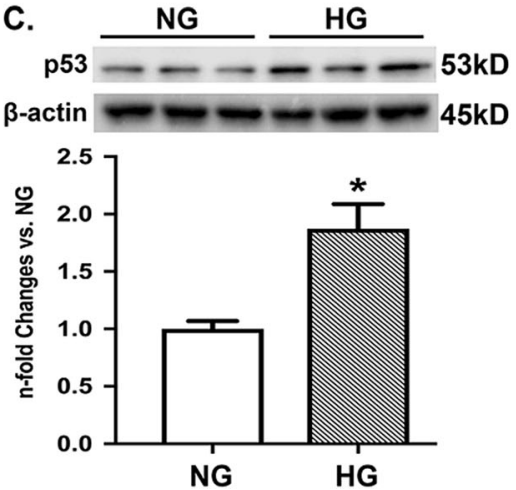

B.
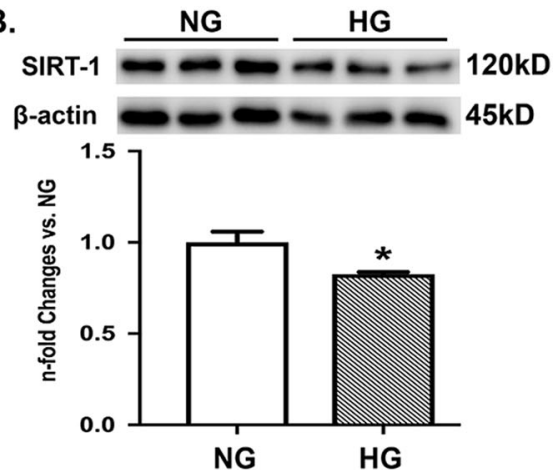

D.

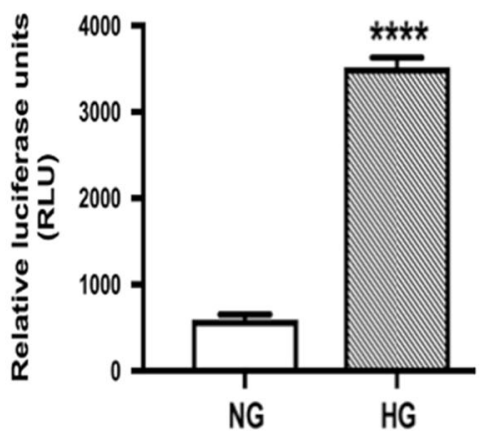

Blood was collected into chilled EDTA tubes, stored on ice and centrifuged at $3220 \times g$ for $10 \mathrm{~min}$ at $4{ }^{\circ} \mathrm{C}$ within 20 min of collection to separate the plasma which was stored in $-80^{\circ} \mathrm{C}$ until further analysis.

\section{Measurement of glucose concentration}

Plasma glucose concentrations were estimated by colorimetric assay, using Glucose Assay Kit (Cayman Chemical), as described earlier [21]. The concentration of glucose for each sample was calculated from the standard curve, and an average $\mathrm{HbAlc}$ was then estimated using the online calculator provided by Diabetes UK (http://www.diabetes.co. uk/hba1c-to-blood-sugar-level-converter.html.).

\section{Diseased human myocardial tissue collection}

Right atrial appendage (RAA) biopsies obtained from the HeartOtago tissue bank were collected from type-2 diabetic $(n=15)$ and non-diabetic $(n=18)$ patients undergoing on-pump coronary artery bypass graft surgery for IHD. Diabetic and non-diabetic patients did not differ significantly in other characteristics aside from type- 2 diabetes. All the patients had HbAlc measured before surgery.

\section{CPCs isolation and culture}

CPCs were isolated using our published protocol [20]. In brief, adipose tissue was removed from the RAA sample before the RAA was digested mechanically and chemically (2\% collagenase II (Worthington Biochemical Corporation, USA). Cells were cultured using Ham's F12 complete media (ThermoFisher, New Zealand) supplemented with $10 \%$ donor bovine serum, human erythropoietin $(0.05 \mathrm{U} / \mathrm{ml}), 10 \mathrm{ng} / \mathrm{ml}$ basic fibroblast growth factor, and $1 \%$ antibiotic-antimycotic. To preserve their epigenetic memory, diabetic CPCs were continued to be cultured in the presence of high glucose $(30 \mathrm{mM})$ throughout the experimental period. Purity of the cells was characterized using flow cytometry for the expression of CD90 and CD105 mesenchymal stem cell markers at the end of two weeks of culture, as described previously [20]. 
A.

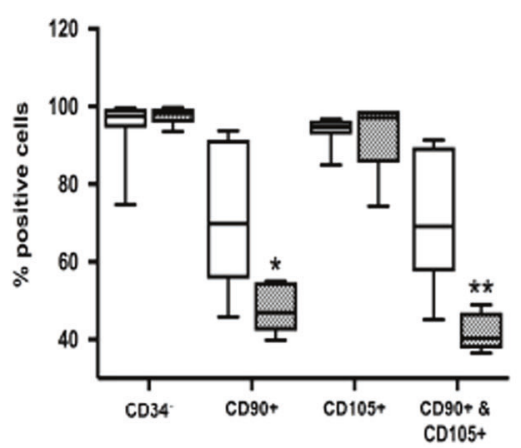

D.
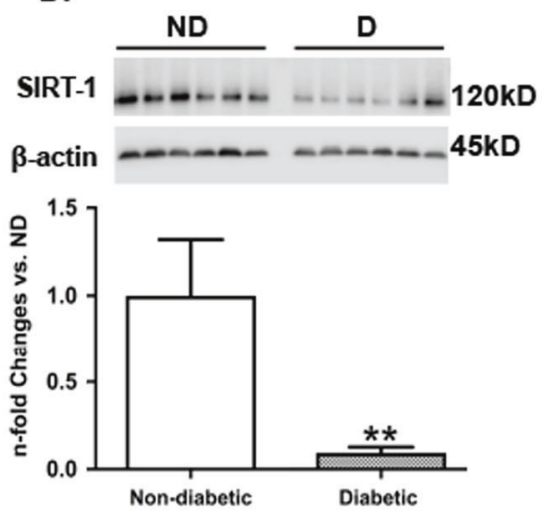

B.
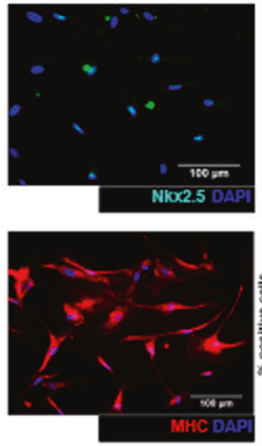
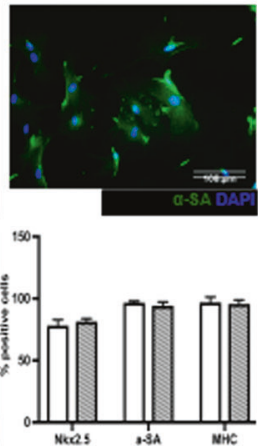

C.

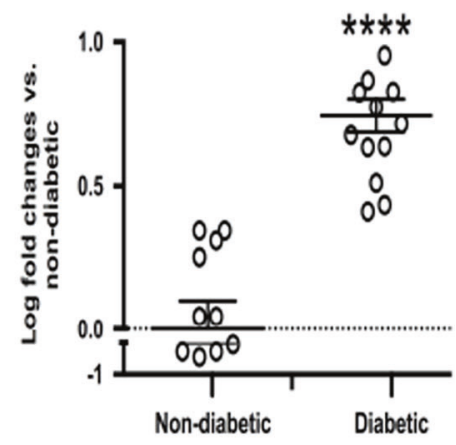

E.
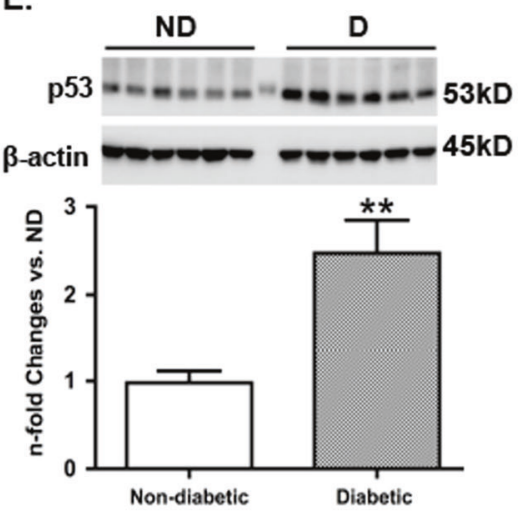

F.

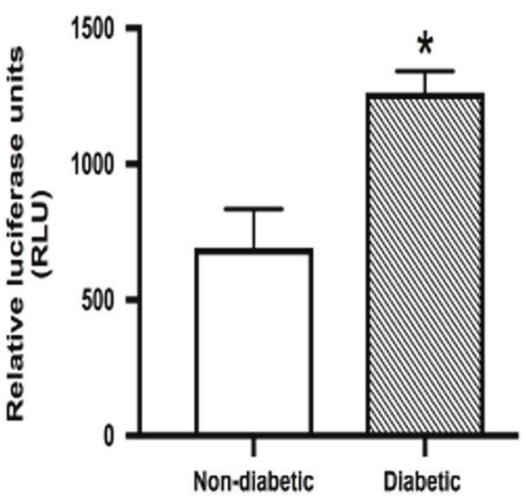

Fig. 5 Diabetes activates miR-34a and increased apoptosis in human diabetic CPCs. a Quantitative box plots showing the expression level of surface antigens CD34, CD90, and CD105 in human CPCs by flow cytometry analysis. Data are represented as percentage $(\%)$ of positive cells. $n=14$ in each group. b Representative immunofluorescence images and quantitative bar graphs showing the expression cardiac markers in differentiated CPCs. Data are represented as percentage (\%) of positive cells. $n=4$ in each group. c Quantitative scatter plots showing the differential expression of miR-34a by quantitative RTPCR analysis in human CPCs. Data are represented as log-fold change

\section{In vitro human ventricular cardiomyocytes cell culture and high glucose experiments}

Human ventricular cardiomyocytes (AC-16) cells were purchased from Davidson Laboratory at the University of Colombia in New York [22]. Cells were maintained and grown in Dulbecco's modified Eagle's medium/F-12 supplemented (DMEM/F12, Life Technologies NZ) with $12.5 \%$ foetal bovine serum, along with $1 \%$ antibioticantimycotic (Life Technologies ${ }^{\mathrm{TM}}$ Gibco ${ }^{\circledR}$, New Zealand) at $37^{\circ} \mathrm{C}$ in $5 \% \mathrm{CO}_{2}$. For the experiments, cells were exposed to high D-glucose $(\mathrm{HG}, 30 \mathrm{mM})$ or D-mannitol (NG, $30 \mathrm{mM}$, used as an osmotic control).

\section{In vitro inhibition of miR-34a activity}

AC-16 ventricular cardiomyocytes/CPCs were seeded at either 5000 cells/well in a 96-well culture dish for caspase- in miR-34a expression vs. non-diabetic CPCs and are mean $\pm \mathrm{SEM}$. $n=14$ in each group. d, e Immunoblot images and quantitative bar graphs showing the expression of SIRT-1 d and p53 e in diabetic and non-diabetic CPCs. $\beta$-actin was used as internal control. Data are represented as fold changes to non-diabetic CPCs and are mean \pm SEM. $n=6$ in each group. f Quantitative bar graphs showing the caspase-3/7 activity in NG and HG cultured cells. Data are represented as relative luciferase units and are mean \pm SEM. $* P<0.05$, $* * P<0.01$, and $* * * * P<0.0001$ vs. non-diabetic CPCs. $n=6$ individual CPC samples in each group

$3 / 7$ activity assay, or 180,000 cells/well in a 6-well culture dish for further molecular analysis. After $48 \mathrm{~h}$ cardiomyocytes were randomized to either NG or HG treatment, followed by transfection $24 \mathrm{~h}$ later with anti-miR-34a or scrambled sequence using Lipofectamine RNAiMAX (all from ThermoFisher Scientific, New Zealand). RNA and protein samples were collected after a further $24 \mathrm{~h}$, along with measurements of caspase-3/7 activity and proliferation potential (vide infra).

\section{RNA isolation and real-time PCR}

Total RNA samples were extracted from plasma, RAA tissue, AC-16 cardiomyocytes, and CPCs using the Qiagen miRNeasy mini kit (Germany). Extracted RNA was quantified with a Nanodrop-1000 spectrophotometer (Nanodrop Technologies). To measure the expression levels of miR$34 \mathrm{a}, 20 \mathrm{ng}$ of total RNA was reverse transcribed using miR- 
Fig. 6 miR-34a activity inhibition reduces apoptotic cell death in high glucose treated human cardiomyocytes. a, b Representative immunoblot images and quantitative bar graphs showing the expression of SIRT- 1 a and $\mathrm{p} 53 \mathbf{b}$ in AC-16 cardiomyocytes following inhibition of miR-34a (anti-miR$34 a)$ activity. $\beta$-actin was used as internal control. Data are represented as fold changes to cardiomyocytes cultured in normal glucose (NG) and are transfected with Scrambled sequence (Scr). Values are mean \pm SEM. c Quantitative bar graphs showing the caspase- $3 / 7$ activity in AC-16 following inhibition of miR-34a (anti-miR34a) activity. Data are represented as relative luciferase units and are mean \pm SEM. $* P<0.05$ and $* * * * P<0.0001$ vs. NG-Scr cells; ${ }^{\#} P<0.05$, ${ }^{\# \# \#} P<0.001$, and ${ }^{\# \# \# \#} P<0.0001$ vs. corresponding Scrambled sequence (Scr) transfected cells. $n=3$ for all the experiments
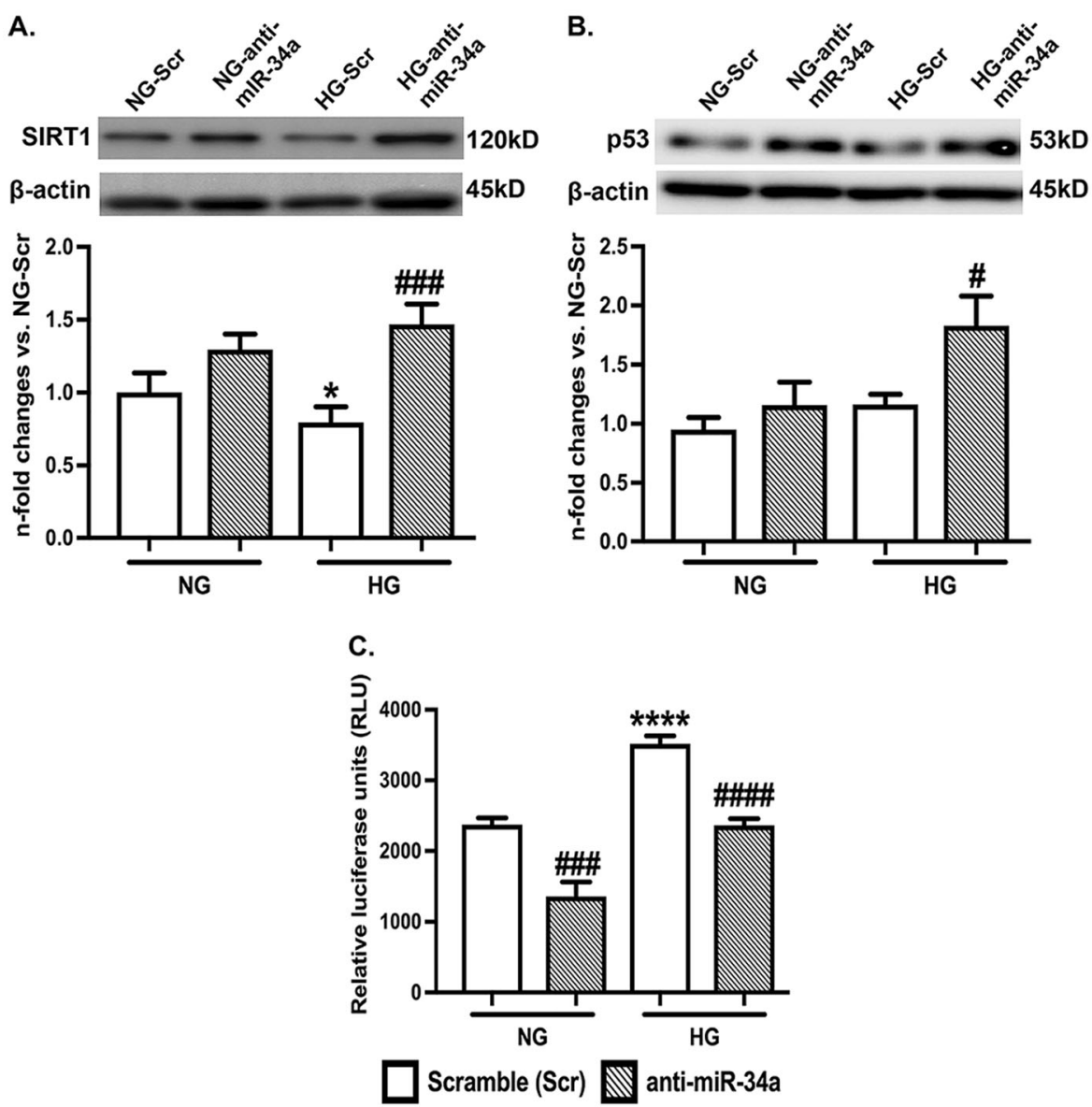

34a specific stem-loop structure and reverse transcription primers followed by amplification using the specific Taqman hybridization probe for miR-34a. MiR-16 and miR-24 were used as endogenous controls for circulating miRs, and U6 small nuclear RNA was used as an endogenous control for tissue and cells (all from Thermo Fisher Scientific). Earlier studies have demonstrated miR-16 and miR-24 as stable endogenous controls during analysis of circulating miRs [23, 24]. Relative expression of miR-34a was determined using $2^{-\Delta \Delta C T}$ method and represented as log-fold change to non-diabetic/normal glucose, as described in our earlier studies $[25,26]$.

\section{Western blot analysis}

Total protein was extracted from tissue and cell samples following homogenization or lysis in ice-cold RIPA lysis buffer (1\% Triton X-100, 0.1\% SDS, $50 \mathrm{mM}$ Tris-HCL (pH7.4), $150 \mathrm{mM} \mathrm{NaCl}, 1 \mathrm{mM}$ EDTA) with PMSF and Complete protease inhibitor cocktail (Roche Diagnostics, USA). Approximately $30 \mu \mathrm{g}$ of total protein as estimated by the Bradford assay was resolved by a 7.5 or $10 \%$ SDS-PAGE gel, and transferred to PVDF membrane to allow probing for Akt (Thermofisher, New Zealand), PNUTS (Santa Cruz Biotechnology, USA), SIRT1 (Cell Signaling, USA), and p53 (Cell Signaling, USA, all 1:1000 dilution), overnight at $4{ }^{\circ} \mathrm{C}$. Fluorescence-conjugated secondary antibodies (Thermofisher, New Zealand, 1:20,000 dilution) were used to probe for Akt and PNUTS and quantified using the Odyssey infrared imaging system (LICOR). HRP-conjugated secondary antibodies (Santa Cruz Biotechnology, USA, 1:2000 dilution) were used to probe for SIRT1 and p53, and bands imaged using the Syngene Pxi Multi-application gel imaging system (Syngene, UK). All bands were analyzed using Image Studio Lite v4.0 (LI-COR).

\section{Caspase-3/7 activity in AC-16 cells and CPCs}

At the end of the cell treatment period, fresh medium was added with an equal amount of caspase-3/7 substrate. Cells were incubated in the dark for $1 \mathrm{~h}$ before measuring the 
Fig. 7 miR-34a activity inhibition is not beneficial in human diabetic CPCs. a, b Representative immunoblot images and quantitative bar graphs showing the expression of SIRT- $1 \mathbf{a}$ and $\mathrm{p} 53 \mathbf{b}$ in human CPCs following inhibition of miR-34a (anti-miR-34a) activity. $\beta$-actin was used as internal control. Data are represented as fold changes to non-diabetic (ND) CPCs transfected with Scrambled sequence (Scr). Values are mean \pm SEM. c Quantitative bar graphs showing the caspase-3/7 activity in AC-16 following inhibition of miR-34a (anti-miR34a) activity. Data are represented as relative luciferase units and are mean \pm SEM. d Quantitative bar graphs showing the number of CPCs at the end of treatment period measured by cyquant assay to determine the proliferation rate following inhibition of miR-34a (anti-miR34a) activity. Data are represented as cell number and are mean \pm SEM. $* P<0.05$ and $* * P<0.01$ vs. ND-Scr CPCs; ${ }^{\# \#} P<0.01$ and ${ }^{\# \# \#} P<0.001$ vs. corresponding Scrambled sequence $(\mathrm{Scr})$ transfected CPCs. All the experiments were performed in CPCs collected from three different patients
A.
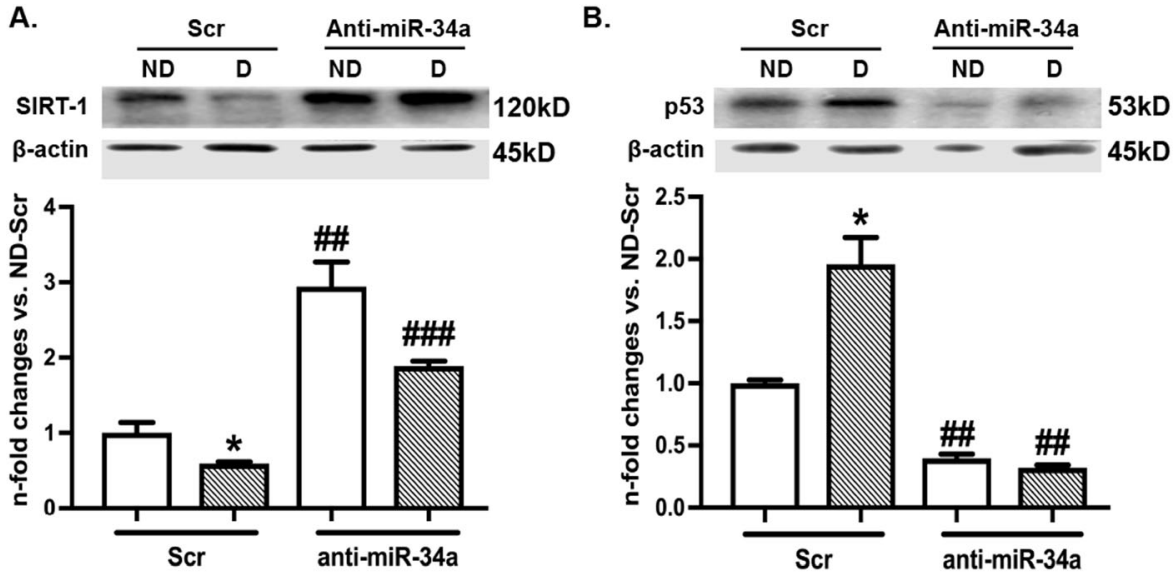

c.

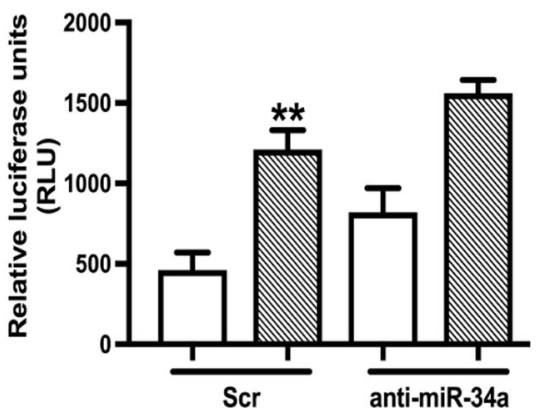

D.

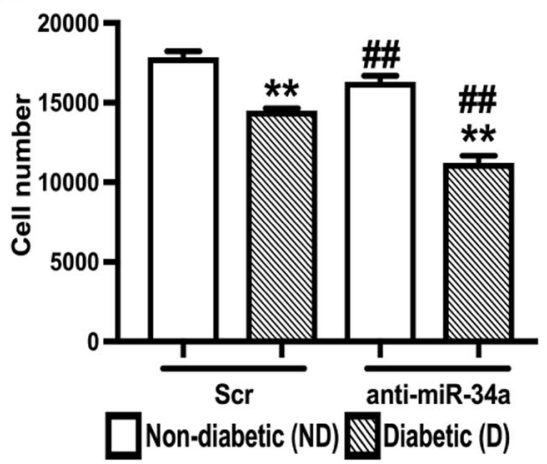

luminescence using the Synergy 2 microplate reader (BioTeK, USA). The background luminescence associated with cell culture and assay reagent (blank reaction) was subtracted from the experimental value.

\section{Proliferation of CPCs}

The CyQuant cell proliferation assay kit (Thermofisher, USA) was used to quantify the cell number, according to the manufacturer's protocol. In brief, at the end of the treatment period growth media was removed from the wells and the plate was stored in $-80{ }^{\circ} \mathrm{C}$ before adding the CyQuant ${ }^{\circledR}$ buffer to each well. Fluorescence was then read at $530 \mathrm{~nm}$ using the Synergy 2 microplate reader (BioTek, USA), and cell number determined using a standard curve.

\section{Statistical analysis}

All data are represented as mean \pm SEM. A student $t$-test was used to compare the statistical differences between two groups, and all comparisons between multiple groups were obtained through a one-way analysis of variance (ANOVA), with a Bonferroni post-hoc test, or the Kruskal-Wallis test, as appropriate. A $p$ value of $<0.05$ was considered significant. All data were analyzed using GraphPad Prism 6.0.

\section{Discussion}

Our results have shown for the first time that diabetes increases the expression of miR-34a both in the heart and circulation. However, this appears to be having differential functional effects on cardiomyocytes and CPCs. To our knowledge, this is the first study to determine the effects of diabetes on miR-34a in human diabetic heart and CPCs. Importantly, activation of miR-34a starts from the early stages of diabetes, as demonstrated by increased circulating miR-34a in diabetic individuals who were otherwise healthy. Moreover, the expression of miR-34a was strongly correlated with HbA1c level, suggesting that increased miR-34a expression is related to high glucose. As miR-34a is abundantly expressed in cardiomyocytes [14], this 
Table 2 Clinical characteristics of study participants without any clinical history of heart disease

\begin{tabular}{|c|c|c|c|c|c|c|c|}
\hline Type & $\begin{array}{l}\text { Study participant } \\
\text { ID }\end{array}$ & Age & Sex & $\begin{array}{l}\text { Duration of } \\
\text { diabetes (years) }\end{array}$ & $\begin{array}{l}\text { Body weight } \\
(\mathrm{kg})\end{array}$ & $\begin{array}{l}\text { Body Mass } \\
\text { Index }\end{array}$ & $\mathrm{HbA} 1 \mathrm{C}$ \\
\hline \multirow[t]{32}{*}{ Non-diabetic } & 46617 & 59 & $\mathrm{~F}$ & 0 & 72 & 30.76 & 45 \\
\hline & 18945 & 54 & M & 0 & 92 & 30.74 & 32 \\
\hline & 30774 & 76 & M & 0 & 84 & 25.08 & 35 \\
\hline & 45944 & 60 & $\mathrm{~F}$ & 0 & 46 & 18.66 & 46 \\
\hline & 26460 & 62 & M & 0 & 71 & 24 & 37 \\
\hline & 29907 & 80 & M & 0 & 67 & 22.65 & 35 \\
\hline & 28444 & 83 & M & 0 & 96 & 29.3 & 38 \\
\hline & 26656 & 49 & M & 0 & 90 & 27.17 & 40 \\
\hline & 29404 & 64 & M & 0 & 83 & 25.06 & 38 \\
\hline & 18622 & 52 & M & 0 & 96 & 28.67 & 43 \\
\hline & 27547 & 87 & M & 0 & 50 & 18.59 & 42 \\
\hline & 28066 & 64 & $\mathrm{~F}$ & 0 & 54 & 20.32 & 40 \\
\hline & 25364 & 79 & $\mathrm{~F}$ & 0 & 61 & 23.83 & 44 \\
\hline & 22304 & 78 & M & 0 & 66 & 23.38 & 35 \\
\hline & 24218 & 63 & M & 0 & 105 & 30.68 & 35 \\
\hline & 29472 & 69 & M & 0 & 90 & 27.78 & 35 \\
\hline & 28197 & 83 & M & 0 & 81 & 24.45 & 45 \\
\hline & 28793 & 85 & M & 0 & 92 & 29.04 & 39 \\
\hline & 27841 & 86 & $\mathrm{~F}$ & 0 & 56 & 24.24 & 36 \\
\hline & 23166 & 48 & M & 0 & 81 & 29.75 & 36 \\
\hline & 20973 & 66 & $\mathrm{~F}$ & 0 & 93 & 33.35 & 45 \\
\hline & 25556 & 63 & M & 0 & 70 & 26.03 & 40 \\
\hline & 22231 & 77 & M & 0 & 62 & 18.31 & 43 \\
\hline & 29867 & 78 & $\mathrm{M}$ & 0 & 84 & 24.54 & 42 \\
\hline & 28295 & 72 & $\mathrm{M}$ & 0 & 79 & 29.73 & 35 \\
\hline & 28635 & 70 & $\mathrm{M}$ & 0 & 85 & 25.38 & 43 \\
\hline & 43956 & 57 & $\mathrm{M}$ & 0 & 118 & 33.74 & 35 \\
\hline & 25735 & 73 & $\mathrm{M}$ & 0 & 92.5 & 29.86 & 43 \\
\hline & 26194 & 76 & M & 0 & 85 & 27.13 & 42 \\
\hline & 35705 & 66 & M & 0 & 95 & 27.17 & 45 \\
\hline & 44875 & 70 & $\mathrm{M}$ & 0 & 86 & 28.73 & 38 \\
\hline & 44277 & 67 & M & 0 & 96 & 27.45 & 45 \\
\hline \multirow[t]{11}{*}{ Diabetic $<5$ years } & 17890 & 48 & M & 1 & 136 & 38.48 & 45 \\
\hline & 20044 & 59 & $\mathrm{~F}$ & 1 & 80 & 28.34 & 52 \\
\hline & 20406 & 61 & M & 1 & 77 & 25.43 & 57 \\
\hline & 21434 & 69 & M & 1 & 80.5 & 23.78 & 42 \\
\hline & 2136 & 77 & M & 3 & 74 & 22.97 & 47 \\
\hline & 5949 & 51 & M & 3 & 91 & 30.41 & 63 \\
\hline & 19290 & 55 & $\mathrm{~F}$ & 3 & 66 & 23.67 & 55 \\
\hline & 6792 & 74 & $\mathrm{M}$ & 4 & 83 & 27.73 & 48 \\
\hline & 7823 & 76 & $\mathrm{M}$ & 4 & 82 & 27.24 & 66 \\
\hline & 8523 & 46 & $\mathrm{M}$ & 4 & 83 & 29.76 & 72 \\
\hline & 20291 & 60 & M & 4 & 98 & 29.26 & 44 \\
\hline \multirow[t]{3}{*}{ Diabetic $5-10$ years } & 21284 & 68 & M & 5 & 75 & 27.89 & 73 \\
\hline & 21629 & 70 & $\mathrm{~F}$ & 5 & 81 & 31.06 & 46 \\
\hline & 727 & 57 & M & 6 & 65 & 22.89 & 54 \\
\hline
\end{tabular}


Table 2 (continued)

\begin{tabular}{|c|c|c|c|c|c|c|c|}
\hline Type & $\begin{array}{l}\text { Study participant } \\
\text { ID }\end{array}$ & Age & Sex & $\begin{array}{l}\text { Duration of } \\
\text { diabetes (years) }\end{array}$ & $\begin{array}{l}\text { Body weight } \\
(\mathrm{kg})\end{array}$ & $\begin{array}{l}\text { Body Mass } \\
\text { Index }\end{array}$ & $\mathrm{HbA} 1 \mathrm{C}$ \\
\hline & 18516 & 51 & M & 6 & 88 & 28.73 & 79 \\
\hline & 1858 & 69 & $\mathrm{~F}$ & 7 & 75.5 & 32.46 & 69 \\
\hline & 11845 & 52 & M & 7 & 99 & 31.96 & 46 \\
\hline & 28666 & 87 & M & 7 & 77 & 25.73 & 53 \\
\hline & 6455 & 66 & M & 8 & 75 & 24.35 & 71 \\
\hline & 7093 & 74 & M & 8 & 88 & 28.73 & 59 \\
\hline & 11910 & 53 & M & 9 & 88 & 28.73 & 44 \\
\hline & 30027 & 84 & M & 9 & 78 & 26.06 & 42 \\
\hline & 445 & 52 & M & 10 & 84 & 25.64 & 43 \\
\hline & 4297 & 76 & $\mathrm{~F}$ & 10 & 55 & 22.89 & 77 \\
\hline & 9725 & 84 & M & 10 & 72 & 27.43 & 69 \\
\hline \multirow[t]{14}{*}{ Diabetic $>10$ years } & 29336 & 49 & M & 11 & 88 & 24.12 & 57 \\
\hline & 30292 & 69 & M & 11 & 63 & 20.57 & 55 \\
\hline & 29229 & 71 & $\mathrm{M}$ & 12 & 94 & 26.88 & 59 \\
\hline & 28747 & 79 & $\mathrm{~F}$ & 14 & 70 & 26.67 & 78 \\
\hline & 8805 & 78 & $\mathrm{M}$ & 15 & 93 & 32.37 & 77 \\
\hline & 10715 & 67 & M & 15 & 92 & 28.71 & 69 \\
\hline & 21709 & 71 & $\mathrm{M}$ & 16 & 87 & 30.10 & 52 \\
\hline & 9254 & 80 & $\mathrm{M}$ & 18 & 75.5 & 22.54 & 61 \\
\hline & 1262 & 64 & $\mathrm{M}$ & 19 & 78 & 24.62 & 49 \\
\hline & 1889 & 62 & $\mathrm{M}$ & 20 & 80 & 26.73 & 69 \\
\hline & 4399 & 76 & $\mathrm{~F}$ & 20 & 65 & 28.13 & 57 \\
\hline & 7321 & 77 & $\mathrm{~F}$ & 22 & 63.5 & 24.50 & 72 \\
\hline & 9849 & 92 & $\mathrm{~F}$ & 24 & 51 & 20.69 & 85 \\
\hline & 503 & 57 & $\mathrm{~F}$ & 25 & 67 & 25.06 & 42 \\
\hline
\end{tabular}

HbA1c - Glycated haemoglobin

suggests that pathological changes mediated through miR34a start early in the diabetic heart.

Circulating miRs have been shown to reflect the disease status of a tissue or organ. Willeit et al., showed a strong association between miR-122 and the development of metabolic syndrome and type 2 diabetes [27]. With regards to the cardiovascular system, Gonzalo-Calvo et al. showed marked dysregulation in the levels of cardiac specific miR-1 and miR-133a in plasma collected from asymptomatic type 2 diabetic individuals [28]. Similarly, Dangwal et al. showed a strong association between circulating miR-191 and impaired wound healing in type 2 diabetic individuals [29]. In our recent study, downregulation of circulating miR-126 and miR-132 were associated with diabetes induced microangiopathy [5]. Although the above studies only correlated circulating miRs expression level to the disease, in the current study we confirmed that the expression level of miR-34a in circulation reflects the expression in myocardium, which was also associated with a marked diminution of pro-survival SIRT1. Therefore, upregulation of circulating miR-34a in asymptomatic diabetic individuals in our study highlights the value of miR-34a, as a diagnostic tool to determine the senescent status of the heart. As miR$34 \mathrm{a}$ expression is upregulated from the early stages of diabetes in diabetic individuals, it will be interesting to determine if similar changes are observed in individuals with glucose intolerance.

Cellular senescence has been implicated as a basic mechanism for many age-related diseases resulting in significant tissue dysfunction. Diabetes induces a variety of cellular stressors such as oxidative stress, DNA damage, and telomere shortening, all of which induce cellular senescence. Within the heart, hyperglycemia accelerates senescence of cardiovascular cells [7, 30], a well-accepted reason for increased incidence of cardiovascular disease in diabetic individuals [31].

Sirtuins (SIRT1), belong to a large family of class III histone deacetylase and were identified as critical regulators of cellular longevity [32]. Cardiac-specific overexpression of SIRT1 markedly inhibited apoptotic cell death in 
cardiomyocytes that were exposed to high oxidative stress [33]. Studies have shown a marked downregulation of SIRT1 as one of the major causes for increased senescence in the diabetic heart [34]. In our study, either diabetes or high glucose markedly increased the expression of miR-34a in the human heart and cardiomyocytes. MiR-34a is a direct regulator of SIRT1, which was further supported by our study showing marked downregulation of SIRT-1 in diabetic heart and high glucose treated cardiomyocytes. Inhibition of miR-34a restored the expression of SIRT1 further confirming the direct regulation of SIRT1 by miR-34a. Increased SIRT1 inhibits p53 expression to promote cell survival [35]. However, in contrast to our expectation, p53 showed a further increase in high glucose cultured cardiomyocytes. MiR-34a and p53 have a functional relationship, with p53 causing transcription of miR-34a which in turn directly inhibits TP53 (the coding gene for p53) [13]. Therefore, while increased SIRT1 expression following inhibition of miR-34a activity reduces p53, this could have also reduced the direct inhibitory effect of miR-34a on TP53, leading to further increase in p53 expression [13]. Irrespective of this large increase in p53, miR-34a inhibition was able to markedly diminish high glucose induced apoptotic cell death. Although p53 is largely known as an activator of apoptotic cell death and senescence, studies have also demonstrated that $\mathrm{p} 53$ can play a cytoprotective role depending on the level of stress [36]. Bensaad et al., showed that TIGAR, a p53-inducible gene, protects the cells from reactive oxygen species (ROS) induced apoptosis [37], and it is well known that high glucose increases ROS in cardiomyocytes [3]. Although we did not measure the expression of TIGAR, we believe that increased p53 could have reduced ROS in high glucose treated cardiomyocytes, which along with increased SIRT1 reduced the apoptotic cell death following inhibition of miR-34a activity (Summarized in Fig. 8). This notion is further supported by results from RAA tissue which failed to show any increase in p53 expression in spite of significant downregulation in SIRT1 expression.

Interestingly, CPCs showed opposite effects following inhibition of miR-34a activity. Although diabetic CPCs showed increased expression of miR-34a as expected, we did not observe any anti-apoptotic effects following its inhibition. Intriguingly, inhibition of miR-34a significantly decreased the expression of p53 in contrast to the cardiomyocytes, while increasing SIRT1. This possibly reduced the antioxidant role of p53 as stated above, resulting in increased apoptotic cell death in diabetic CPCs following miR-34a inhibition (summarized in Fig. 7). Although the exact reason for this contrasting results is not known, a recent study by Navarro et al., showed that miR-34a has differential effects on p53 depending on the cell type [13]. Moreover, CPCs in our study were isolated from a diabetic heart, while experiments with cardiomyocytes were performed following treatment with high glucose. This is a reasonable limitation for our study provided that it is technically not feasible to isolate and culture adult cardiomyocytes.

In addition to increased apoptosis, miR-34a inhibition significantly decreased the proliferation of diabetic CPCs suggesting that miR-34a may be required for the proliferation of CPCs under hyperglycaemic stress. This is consistent with a recently published study by Zhang et al.,
Fig. 8 Differential effects of miR-34a in cardiomyocytes and cardiac progenitor cells (CPCs). Cartoon image depicting differential effects of miR-34a on cell survival and proliferation in cardiomyocytes and CPCs. miR-34a reduces cell survival through inhibition of SIRT-1 and through activation of TP53 the gene encoding P53 protein. Therefore inhibition of miR-34a increases SIRT-1, but at the same time possibly increases the anti-oxidant ability of P53. In contrast, miR-34a mediated pathway may be playing a beneficial role in CPCs through ROS generation which is required for stem cells survival and proliferation. Inhibition of miR-34a reduced P53 thereby eliminating the protective effects of ROS
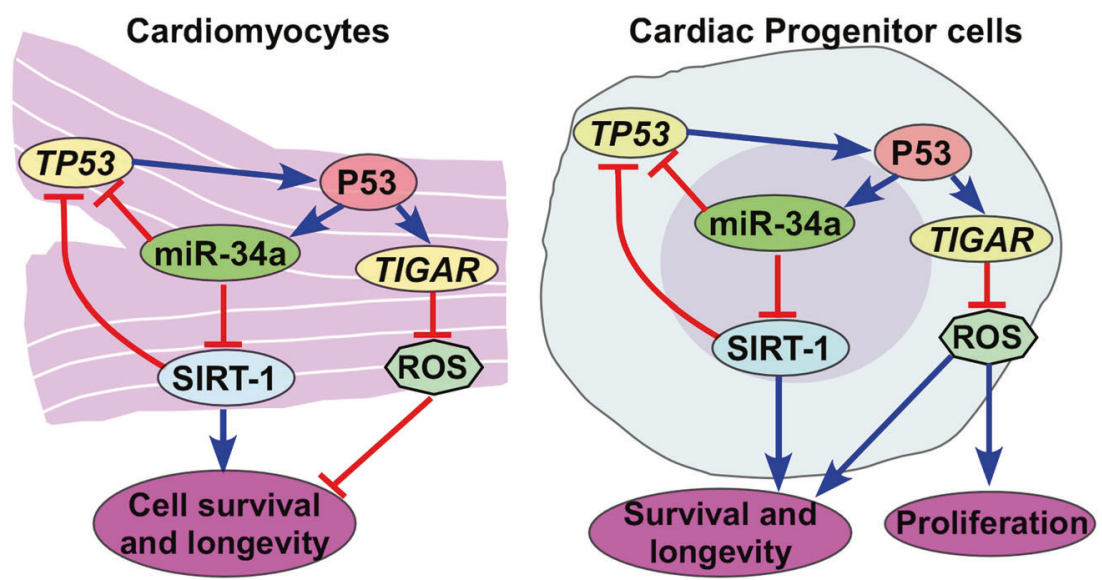
where mesangial cells isolated from type- 2 diabetic $\mathrm{db} / \mathrm{db}$ mice demonstrated an increase in miR-34a expression and a detrimental increase in proliferation, a hallmark of diabetic nephropathy. MiR-34a inhibition was able to alleviate the adversely enhanced mesangial cell proliferation [38]. In another study, overexpression of miR-34a promoted proliferation of neuronal progenitor cells [39]. Further, Maddocks et al., demonstrated that tumor cells lacking p53 exhibited reduced viability and impaired proliferation [40]. As, stem cells exhibit similar properties of cancer cells with regards to its ability to proliferate under stressful conditions [41], it is possible that CPCs require p53 for proliferation.

Taken together, our results demonstrate that diabetes/ high glucose induces upregulation of miR-34a from an early stage of the disease. However, inhibition of miR-34a activity has differential effects depending on the type of the cell. MiRNA mediated therapy is gaining huge interest with at least four clinical trials including one with miR-34a currently in progress [42]. As most of the miR therapy is designed for systemic administration, our results indicate that it is crucial to determine and eliminate the possible adverse effects due to its undesirable off-target effect of this novel treatment approach. Moreover, our results showing upregulation of miR-34a from the early stages of diabetes will lay foundation for future studies to establish miR$34 \mathrm{a}$, as a diagnostic tool for determining the senescence of heart.

Acknowledgements We would like to thank Mrs Jayanthi Bellae Papannarao for technical assistance in extracting RNA from plasma samples for the experiments performed during revision. This study was supported by New Zealand Society for the Study of Diabetes; Heart Foundation NZ (1600 and 1698); Royal Society of New Zealand Catalyst Seed Funding (CSG-U001601), Otago School Of Medical Sciences Dean's Bequest funding; Otago Medical Research Foundation (AG307); Lottery Health Board Grant (LHR-2017- 46886) and University of Otago Research Grant. The Canterbury Healthy Volunteers Study was funded by grants from the Health Research Council and by the University of Otago, Christchurch.

\section{Compliance with ethical standards}

Conflict of interest The authors declare that they have no conflict of interest.

Open Access This article is licensed under a Creative Commons Attribution-NonCommercial-NoDerivatives 4.0 International License, which permits any non-commercial use, sharing, distribution and reproduction in any medium or format, as long as you give appropriate credit to the original author(s) and the source, and provide a link to the Creative Commons license. You do not have permission under this license to share adapted material derived from this article or parts of it. The images or other third party material in this article are included in the article's Creative Commons license, unless indicated otherwise in a credit line to the material. If material is not included in the article's Creative Commons license and your intended use is not permitted by statutory regulation or exceeds the permitted use, you will need to obtain permission directly from the copyright holder. To view a copy of this license, visit http://creativecommons.org/licenses/by-nc-nd/4.0/.

\section{References}

1. IDF. Diabetes Atlas. 2014. http://www.idf.org/diabetesatlas

2. Munasinghe PE, Riu F, Dixit P, Edamatsu M, Saxena P, Hamer NS, et al. Type-2 diabetes increases autophagy in the human heart through promotion of Beclin-1 mediated pathway. Int J Cardiol. 2016;202:13-20.

3. Katare RG, Caporali A, Oikawa A, Meloni M, Emanueli C, Madeddu P. Vitamin B1 analog benfotiamine prevents diabetesinduced diastolic dysfunction and heart failure through Akt/Pim1-mediated survival pathway. Circ Heart Fail. 2010;3:294-305.

4. Oikawa A, Siragusa M, Quaini F, Mangialardi G, Katare RG, Caporali A, et al. Diabetes mellitus induces bone marrow microangiopathy. Arterioscler Thromb Vasc Biol. 2010;30: 498-508.

5. Rawal S, Munasinghe PE, Shindikar A, Paulin J, Cameron V, Manning P, et al. Down-regulation of proangiogenic microRNA126 and microRNA-132 are early modulators of diabetic cardiac microangiopathy. Cardiovasc Res. 2017;113:90-101.

6. Katare R, Oikawa A, Cesselli D, Beltrami AP, Avolio E, Muthukrishnan D, et al. Boosting the pentose phosphate pathway restores cardiac progenitor cell availability in diabetes. Cardiovasc Res. 2013;97:55-65.

7. Rota M, LeCapitaine N, Hosoda T, Boni A, De Angelis A, PadinIruegas ME, et al. Diabetes promotes cardiac stem cell aging and heart failure, which are prevented by deletion of the p66shc gene. Circ Res. 2006;99:42-52.

8. Asmal AC, Leary WP, Thandroyen F. Diabetic heart disease. S Afr Med J. 1980;57:788-90.

9. McDaniel CF. Diabetes: a model of oxidative accelerated aging. Age. 1999;22:145-8.

10. Giacco F, Brownlee M. Oxidative stress and diabetic complications. Circ Res. 2010;107:1058-70.

11. Creemers EE, Tijsen AJ, Pinto YM. Circulating microRNAs: novel biomarkers and extracellular communicators in cardiovascular disease? Circ Res. 2012;110:483-95.

12. Wightman B, Burglin TR, Gatto J, Arasu P, Ruvkun G. Negative regulatory sequences in the lin-14 $3^{\prime}$-untranslated region are necessary to generate a temporal switch during Caenorhabditis elegans development. Genes Dev. 1991;5:1813-24.

13. Navarro F, Lieberman J. miR-34 and p53: new insights into a complex functional relationship. PLoS ONE. 2015;10:e0132767.

14. Boon RA, Iekushi K, Lechner S, Seeger T, Fischer A, Heydt S, et al. MicroRNA-34a regulates cardiac ageing and function. Nature. 2013;495:107-10.

15. Bernardo BC, Gao XM, Winbanks CE, Boey EJ, Tham YK, Kiriazis $\mathrm{H}$, et al. Therapeutic inhibition of the miR-34 family attenuates pathological cardiac remodeling and improves heart function. Proc Natl Acad Sci USA. 2012;109:17615-20.

16. Cao W, Fan R, Wang L, Cheng S, Li H, Jiang J, et al. Expression and regulatory function of miRNA-34a in targeting survivin in gastric cancer cells. Tumour Biol. 2013;34:963-71.

17. Yamakuchi M, Ferlito M, Lowenstein CJ. miR-34a repression of SIRT1 regulates apoptosis. Proc Natl Acad Sci USA. 2008;105:13421-6.

18. Thong FS, Bilan PJ, Klip A. The Rab GTPase-activating protein AS160 integrates Akt, protein kinase C, and AMP-activated protein kinase signals regulating GLUT4 traffic. Diabetes. 2007;56:414-23.

19. Brunet A, Sweeney LB, Sturgill JF, Chua KF, Greer PL, Lin Y, et al. Stress-dependent regulation of FOXO transcription factors by the SIRT1 deacetylase. Science. 2004;303:2011-5. 
20. Dixit P, Donnelly H, Edamatsu M, Galvin I, Bunton R, Katare R. Progenitor cells from atria, ventricle and peripheral blood of the same patients exhibit functional differences associated with cardiac repair. Int J Cardiol. 2017;228:412-21.

21. Moore A, Shindikar A, Fomison-Nurse I, Riu F, Munasinghe PE, Ram TP, et al. Rapid onset of cardiomyopathy in STZ-induced female diabetic mice involves the downregulation of pro-survival Pim-1. Cardiovasc Diabetol. 2014;13:68.

22. Davidson MM, Nesti C, Palenzuela L, Walker WF, Hernandez E, Protas L, et al. Novel cell lines derived from adult human ventricular cardiomyocytes. J Mol Cell Cardiol. 2005;39:133-47.

23. Marabita F, de Candia P, Torri A, Tegner J, Abrignani S, Rossi RL. Normalization of circulating microRNA expression data obtained by quantitative real-time RT-PCR. Brief Bioinform. 2016;17:204-12.

24. Xiang M, Zeng Y, Yang R, Xu H, Chen Z, Zhong J, et al. U6 is not a suitable endogenous control for the quantification of circulating microRNAs. Biochem Biophys Res Commun. 2014;454:210-4.

25. Rawal S, Ram TP, Coffey S, Williams MJ, Saxena P, Bunton RW, et al. Differential expression pattern of cardiovascular microRNAs in the human type-2 diabetic heart with normal ejection fraction. Int J Cardiol. 2016;202:40-43.

26. Katare R, Rawal S, Munasinghe PE, Tsuchimochi H, Inagaki T, Fujii $\mathrm{Y}$, et al. Ghrelin promotes functional angiogenesis in a mouse model of critical limb ischemia through activation of proangiogenic microRNAs. Endocrinology. 2016;157:432-45.

27. Willeit P, Skroblin P, Moschen AR, Yin X, Kaudewitz D, Zampetaki A, et al. Circulating microRNA-122 is associated with the risk of new-onset metabolic syndrome and type 2 Diabetes. Diabetes. $2017 ; 66: 347-57$.

28. de Gonzalo-Calvo D, van der Meer RW, Rijzewijk LJ, Smit JW, Revuelta-Lopez E, Nasarre L, et al. Serum microRNA-1 and microRNA-133a levels reflect myocardial steatosis in uncomplicated type 2 diabetes. Sci Rep. 2017;7:47.

29. Dangwal S, Stratmann B, Bang C, Lorenzen JM, Kumarswamy R, Fiedler J, et al. Impairment of wound healing in patients with type 2 diabetes mellitus influences circulating microRNA patterns via inflammatory cytokines. Arterioscler Thromb Vasc Biol. 2015;35:1480-8.

30. Rawal S, Munasinghe PE, Nagesh PT, Lew JKS, Jones GT, Williams MJA, et al. Down-regulation of miR-15a/b accelerates fibrotic remodelling in the Type 2 diabetic human and mouse heart. Clin Sci. 2017;131:847-63.
31. Fox CS, Golden SH, Anderson C, Bray GA, Burke LE, de Boer $\mathrm{IH}$, et al. Update on prevention of cardiovascular disease in adults with type 2 diabetes mellitus in light of recent evidence: a scientific statement from the American Heart Association and the American Diabetes Association. Diabetes Care. 2015; 38:1777-803.

32. Imai S, Armstrong CM, Kaeberlein M, Guarente L. Transcriptional silencing and longevity protein $\mathrm{Sir} 2$ is an NAD-dependent histone deacetylase. Nature. 2000;403:795-800.

33. Alcendor RR, Gao S, Zhai P, Zablocki D, Holle E, Yu X, et al. Sirt1 regulates aging and resistance to oxidative stress in the heart. Circ Res. 2007;100:1512-21.

34. Sulaiman M, Matta MJ, Sunderesan NR, Gupta MP, Periasamy M, Gupta M. Resveratrol, an activator of SIRT1, upregulates sarcoplasmic calcium ATPase and improves cardiac function in diabetic cardiomyopathy. Am J Physiol Heart Circ Physiol. 2010;298:H833-43.

35. Luo J, Nikolaev AY, Imai S, Chen D, Su F, Shiloh A, et al. Negative control of p53 by Sir2alpha promotes cell survival under stress. Cell. 2001;107:137-48.

36. Gottlieb E, Vousden KH. p53 regulation of metabolic pathways. Cold Spring Harb Perspect Biol. 2010;2:a001040.

37. Bensaad K, Tsuruta A, Selak MA, Vidal MN, Nakano K, Bartrons $\mathrm{R}$, et al. TIGAR, a p53-inducible regulator of glycolysis and apoptosis. Cell. 2006;126:107-20.

38. Zhang L, He S, Guo S, Xie W, Xin R, Yu H, et al. Downregulation of miR-34a alleviates mesangial proliferation in vitro and glomerular hypertrophy in early diabetic nephropathy mice by targeting GAS1. J Diabetes Complicat. 2014;28:259-64.

39. Mollinari C, Racaniello M, Berry A, Pieri M, de Stefano MC, Cardinale A, et al. miR-34a regulates cell proliferation, morphology and function of newborn neurons resulting in improved behavioural outcomes. Cell Death Dis. 2015;6:e1622.

40. Maddocks OD, Berkers CR, Mason SM, Zheng L, Blyth K, Gottlieb E, et al. Serine starvation induces stress and p53dependent metabolic remodelling in cancer cells. Nature. 2013;493:542-6.

41. Scholch S, Garcia SA, Iwata N, Niemietz T, Betzler AM, Nanduri LK, et al. Circulating tumor cells exhibit stem cell characteristics in an orthotopic mouse model of colorectal cancer. Oncotarget. 2016;7:27232-42.

42. Christopher AF, Kaur RP, Kaur G, Kaur A, Gupta V, Bansal P. MicroRNA therapeutics: discovering novel targets and developing specific therapy. Perspect Clin Res. 2016;7:68-74. 